\title{
Introduction to the International Business and Born Digitals Minitrack
}

\author{
Mika Gabrielsson \\ University of Eastern \\ Finland \\ mika.gabrielsson@uef.fi
}

\author{
Minna Rollins \\ University of West \\ Georgia \\ mrollins@westga.edu
}

\author{
Arto Ojala \\ University of Vaasa \\ arto.ojala@uwasa.fi
}

\author{
Sara Fraccastoro \\ University of Eastern \\ Finland \\ sara.fraccastoro@uef.fi
}

The International Business and Born Digitals minitrack focuses on advancing knowledge on the cross-pollination of international business and digitalization, by looking at the role and the characteristics of born global and digital firms. Our minitrack aims at covering the broad issues related to the role of digital artifacts and business models in early internationalizing firms, which is a relatively new and unexplored research area.

The early internationalizing is a central focus because many of the digital firms approach international markets from inception. The success of their international business operations and marketing depends on the effective learning, cultural sensitivity, and knowledge management. This investigation has potential to contribute on literature at the intersection of international business and information systems science research.

This year, there are two papers in our minitrack. The first paper is "Digital entrepreneurial internationalizers: Definitions, Theoretical implications, and Research avenues" by Mika Gabrielsson, Sara Fraccastoro Arto Ojala, and Minna Rollins [1]. The second paper is "Business Model Innovation in the Internationalization of SMEs: the Role of Causation and Effectuation" by Agnes Asemokha, Jackson Musona, Ali Ahi, Lasse Torkkeli, and Sami Sareenketo [2].

Recent research in fields of International Business and Information Systems has advanced our understanding of digital entrepreneurship and how digitalization impacts on internationalization of the firms. However, it still lacks a clear understanding of what constitutes a Born Global \& Digital. Gabrielsson et al. [1] aim at creating an improved conceptualization of Born Global \& Digital firms. Authors review previous studies within the fields of Digital Entrepreneurship, Digitalization, and International Entrepreneurship. First, Gabrielsson et al. [1] develop the criteria to define what constitutes a digital firm, and then pinpoint the term Digital Entrepreneurial Internationalizers (DEIs). DEI is an umbrella term used to refer to the firms that approach internationalization and digitalization at different phases in the firms' history. The categorization yields to a matrix, in which four categories of DEIs emerge.
The authors present real life business examples to explain the characteristics and the behavior of the firms and their approach to both internationalization and digitalization. The most theoretically and empirically interesting and relevant typology of the firms is the "Born Global \& Digital firm" given its timely managerial relevance in today's business endeavor.

Gabrielsson et al. [1] further discuss how the emerging type of firms can affect existing International Business theories and traditional views of the firm and conclude the paper by proposing the avenues for future research on the topic. In particular, Gabrielsson et al. [1] call for the studies that combine the fields of internationalization, entrepreneurship, and digitalization.

The authors of the second paper, Asemokha et al. [2] focus on the different life cycle transitions that Small and Medium-sized Enterprises undergo. The transitions affect their business models when entering foreign markets. The authors state that there is a lack of studies exploring the influence of decision-makers on the business model, when seeking internationalization success.

Asemokha et al. [2] respond to this gap in the research by examining the nexus of effectuation and causation and how the combined effects of these logics influence business model innovation as SMEs internationalize. By reviewing the existing literature, the authors develop propositions that link business model innovation and decision-making logic in international entrepreneurship. Asemokha et al. [2] suggest that the propositions could be tested with the empirical data.

\section{References}

[1] M. Gabrielsson, S. Fraccastoro, A. Ojala, and M. Rollins, "Digital Entrepreneurial Internationalizers: Definitions, Theoretical Implications, and Research Avenues", HICSS, 54, 5-8, January 2021.

[2] A. Asemokha, J. Musona, A. Ahi, L. Torkkeli, and S. Sareenketo, "Business Model Innovation in the Internationalization of SMEs: The Role of Causation and Effectuation”, HICSS, 54, 5-8, January 2021. 